\title{
Size is not everything: differing activity and foraging patterns between the sexes in a monomorphic mammal
}

\author{
Hanna Kavli Lodberg-Holm ${ }^{1}$ (D) S.M.J.G. Steyaert ${ }^{1,2} \cdot$ S. Reinhardt ${ }^{1} \cdot$ F. Rosell ${ }^{1}$ \\ Received: 11 May 2020 / Revised: 11 March 2021 / Accepted: 16 March 2021 / Published online: 5 April 2021 \\ (C) The Author(s) 2021, corrected publication 2021
}

\begin{abstract}
Animals balance foraging with other activities, and activity patterns may differ between sexes due to differing physical requirements and reproductive investments. Sex-specific behavioural differences are common in sexually dimorphic mammals, but have received limited research attention in monomorphic mammals where the sexes are similar in body size. Eurasian beavers (Castor fiber) are obligate monogamous and monomorphic mammals and a good model species to study sex-specific differences. As females increase energy expenditure during reproduction, we hypothesized differing seasonal activity budgets, circadian activity rhythms and foraging patterns between male and reproducing female beavers. To test this hypothesis, we equipped adult beavers with VHF transmitters ( $N=41 ; 16$ female, 25 male) and observed them throughout their active period at night from spring to late summer. Occurrence of their main activities (foraging, travelling and being in lodge) and use of food items (trees/shrubs, aquatic vegetation and herbs/grasses) were modelled to investigate sex-specific seasonal activity budgets and circadian activity rhythms. The sexes did not differ in time spent foraging across the season or night, but during spring, females resided more in the lodge and travelled less. Males and females both foraged on aquatic vegetation during spring, but females used this food source also during late summer, whereas males mostly foraged on trees/shrubs throughout the year. We conclude that seasonal activity budgets and foraging differ subtly between the sexes, which may relate to different energy budgets associated with reproduction and nutritional requirements. Such subtle seasonal behavioural adaptions may be vital for survival and reproduction of monomorphic species.
\end{abstract}

\section{Significance statement}

Activity budgets and foraging patterns of animals are key to their survival and may differ between males and females with different body sizes and physical requirements. In monomorphic species, where males and females have similar body sizes, fewer differences are expected, but may still be pronounced during certain times of the year. We modelled sex-specific seasonal activity budgets and circadian activity rhythms and use of food items in a monomorphic mammal, the Eurasian beaver. By treating season and time of day as a continuous variable rather than modelling differences within distinct predefined periods, we identified subtle sex-specific seasonal trends in activity budgets and use of food items.

Keywords Activity $\cdot$ Castor fiber $\cdot$ Foraging $\cdot$ Eurasian beaver $\cdot$ Monomorphic $\cdot$ Sex

Communicated by T. Stankowich

Hanna Kavli Lodberg-Holm hal@usn.no

1 Faculty of Technology, Natural Sciences and Maritime Sciences, Department of Natural Sciences and Environmental Health, University of South-Eastern Norway, Bø i Telemark, Norway

2 Faculty of Biosciences and Aquaculture, Nord University, NO-7711, Steinkjer, Norway

\section{Introduction}

Foraging is vital for an animal's fitness, and foraging behaviour is optimized in order to maximize intake of resources (Drickamer et al. 2002; Owen-Smith et al. 2010). Animals must balance their energetic needs against the costs of foraging, such as predation risk and thermoregulation (Brown et al. 1999; Zub et al. 2009), and against time spent on other behaviours such as territory defence (Ydenberg and Krebs 1987). The 24-h luminance cycle of night and day usually regulates the circadian rhythm of several species, which may also vary 
seasonally (Hut et al. 2012). Species such as Svalbard reindeer (Rangifer tarandus platyrhynchus) (Arnold et al. 2018) display very stable activity patterns despite extreme difference in light conditions, while others, such as brown bears (Ursus arctos), hibernate during winter and forage intensely during summer (Hertel et al. 2016). Animals may also display strong seasonal foraging patterns linked to plant phenology (Bischof et al. 2012), switching to seasonally abundant food sources (McLellan and Hovey 1995), or building up of food caches in autumn or following masting events (Humphries et al. 2002).

Seasonal activity budgets, circadian activity rhythms and diet may vary in relation to sex, age and reproductive status. Several studies have indicated differences in activity budgets and foraging between the sexes in dimorphic species, with body size as the assumed main driver, but differing investments in reproduction between the sexes may also play a role (Pelletier and Festa-Bianchet 2004; Ruckstuhl 2007). Much of the work on monomorphic species has focused on sea birds in relation to reproductive roles of males and females (Lewis et al. 2002; Shaffer et al. 2003; Hedd et al. 2014; Burke et al. 2015). In mammals, the lactation period increases energetic requirements of females and may cause differences in foraging behaviour and habitat selection between the sexes (Clutton-Brock et al. 1982; Logan and Sanson 2003; Ruckstuhl et al. 2005). Lactation is both energetically costly for females, but also requires additional nutrients, which may increase investments in foraging, decrease time spent on other activities and/or cause dietary changes (Speakman 2008; Rödel et al. 2015). In monomorphic racoon dogs (Nyctereutes procyonoides), females increased foraging during lactation (Zoller and Drygala 2013), while female redtailed sportive lemurs (Lepilemur ruficaudatus) selected food items with overall lower fibre content (Ganzhorn et al. 2004). Differences in activity budgets have also been observed in monomorphic mammals outside the reproductive season, such as female red ruffed lemurs (Varecia rubra) that fed and rested more than males throughout the year (Vasey 2005). However, in monogamous and monomorphic African oryx (Oryx gazella), no differences in activity budgets or foraging intensity of males and females were documented (Ruckstuhl and Neuhaus 2009). Overall, differences in foraging behaviour of males and females in monomorphic species have received less research attention than sex differences in size-dimorphic species (Lewis et al. 2002; Pérez-Barbería et al. 2002). Due to the energetic impact of reproduction on females, such differences may be temporally specific, present only at certain times of the year. Studies commonly use predefined temporal units such as seasons or night/day to statistically compare activity budgets and use of dietary items, which may miss more subtle temporal variations (Lewis et al. 2002; Vasey 2005; Zoller and Drygala 2013). Including time as predefined categories may also simplify more complex trends when exploring animal interactions with the environment (Richter et al. 2020). In this paper, we explore whether males and females in a monogamous and monomorphic mammal display differing temporal trends in activity budgets and circadian activity rhythms and use of food resources, while using time as a continuous variable and the Eurasian beaver (Castor fiber) as a model species.

The Eurasian beavers, together with the closely related North American beaver (Castor canadensis), are obligate monogamous and monomorphic mammals with similar body mass of males and females (Wilsson 1971; Novak 1999; Sun 2003). Beavers are territorial and typically live in family groups consisting of the dominant reproductive pair and offspring from the current and previous years. The kits are born in May-June, after which the dominant pair display a high degree of biparental care with both parents supplying the kits with food inside the lodge until they forage by themselves in late summer (Wilsson 1971; Novak 1999; Sun 2003). The female is still the primary caregiver for the kits during the first 90 days while lactating, which restricts her movements outside the lodge (Żurowski et al. 1974; Mayer et al. 2017a). Beavers are mostly active between dusk and dawn (Sharpe and Rosell 2003; Mott et al. 2011; Swinnen et al. 2015), but may display regional as well as seasonal variation in circadian activity rhythms (Potvin and Bovet 1975; Nolet and Rosell 1994; Gallant et al. 2004). At night, beavers spend much of their time foraging, but this is balanced with travelling and being in the lodge (Sharpe and Rosell 2003; Mott et al. 2011).

Beavers are central place foragers, which implies that they reduce foraging intensity and become more selective with further distance from their central place, i.e. their lodges and the water (Gallant et al. 2004; Haarberg and Rosell 2006; Gerwing et al. 2013). They are also selective foragers on woody vegetation (Fryxell and Doucet 1993; Nolet et al. 1994), but their diet varies seasonally from relying mostly on the bark of deciduous trees during winter to more nutritionally rich deciduous leaves, aquatic vegetation and herbaceous plants during summer (Svendsen 1980; Roberts and Arner 1984; Milligan and Humphries 2010). Several studies have indicated such seasonal shifts in diet, but few dietary differences between the sexes (Roberts and Arner 1984; KrojerováProkešová et al. 2010; Bełżecki et al. 2018). However, most dietary studies rely on histological analysis of beaver scats or stomach content, which may be biased towards less digestible food items (Nielsen et al. 2018).

Previous studies have identified few differences in activity and foraging patterns between male and female beavers, although some differences are related to age. Beaver kits foraged less on land, while older individuals increased time spent away from the water, possibly due to increased boldness with age (Svendsen 1980; Graf et al. 2016). Male beavers also tend to travel more and have longer activity periods than females (Sharpe and Rosell 2003). There have been limited number of studies comparing activity budgets between the sexes and age groups in beavers, and such studies have typically compared 
occurrences of activity types between seasons or periods of the night (Sharpe and Rosell 2003). Especially in monomorphic and monogamous mammals such as beavers, differences between the sexes may be subtle and limited to specific time periods, requiring in-depth temporal exploration of seasonal and circadian activity budgets and foraging.

Our goal was to model the beavers' seasonal activity budgets, circadian activity rhythms and foraging patterns to test to what extent sex-specific differences in behaviour occur. We hypothesize that females have greater energetic demands during gestation and lactation in late spring. Therefore, we predict that females should forage more, travel less and spend more time in the lodge compared to males during spring and during an average night (a). In summer, we predict that females will spend less time in lodge and travel and forage more than males to compensate for energetic expenditures related to reproduction incurred during the spring (b). Additionally, we predict that in spring and in the summer months following reproduction, females should forage more on nutrient-rich plant groups such as aquatic vegetation, herbs and grasses that require less handling time (c). We also accounted for the age of the beaver and distance to the main lodge as potential explanatory variables.

\section{Methods}

\section{Study area}

The study area is located in South-Eastern Norway and includes three rivers: Gvarv, Sauar and Straumen (59 $\left.23^{\prime} \mathrm{N}, 09^{\circ} 09^{\prime} \mathrm{E}\right)$ located in Midt-Telemark and Nome municipalities. The mean daily temperature is $6.5^{\circ} \mathrm{C}$, and the mean daily precipitation is $2.3 \mathrm{~mm}$ (eKlima 2020). Combined, the rivers extend approximately $32 \mathrm{~km}$ and are between 30 to $150 \mathrm{~m}$ wide. All three rivers empty into Norsjø Lake. The rivers meander through a relatively flat area of boreal forests as well as agricultural fields, pastures and small villages where short sections of the rivers freeze during winter. The Gvarv and Straumen rivers are regulated by hydropower dams upriver from the study area (Haarberg and Rosell 2006). The most common woody vegetations along the river are grey alder (Alnus incana), bird cherry (Prunus padus), common ash (Fraxinus excelsior), rowan (Sorbus aucuparia), alder buckthorn (Frangula alnus), birch (Betula spp.), red elderberry (Sambucus racemosa), Norway spruce (Picea abies) and Scots pine (Pinus sylvestris) (Haarberg and Rosell 2006). The most common aquatic species in the rivers include bulbous rush (Juncus bulbosus bulbosus), water lobelia (Lobelia dortmanna), lake quillwort (Isoetes lacustris), shoreweed (Littorella uniflora) and water awlwort (Subularia aquatica) (Hjønnevåg 2020). The area supports a high-density beaver population with long-term stable territories (Mayer et al. 2019), which has been monitored as part of the Norwegian Beaver Project since 1997 (Halley and Rosell 2002;
Campbell et al. 2005). Large carnivores such as wolves (Canis lupus) and bears have been extirpated from the area, but lynx (Lynx lynx) are in low densities (Rosell and Sanda 2006). Red foxes have been observed preying on beaver kits (Kile et al. 1996) and are common throughout South-Eastern Norway (Pedersen et al. 2016).

\section{Live capture}

Beavers were live captured at night using landing nets from boats with outboard engines from March to September during the years 2000, 2001, 2006 and 2007, adhering to vetted methods (Rosell and Hovde 2001). We transferred the captured beaver to a cloth sack, in which it was measured and tagged. Age was estimated based on either previous observations of the beaver as a kit or based on minimum age estimated from body weight (Rosell et al. 2010). Beavers captured for the first time weighing $\geq 17 \mathrm{~kg}$ and $\leq 19.5 \mathrm{~kg}$ were considered at least 2 years old, while those $>19.5 \mathrm{~kg}$ were at minimum 3 years old (Rosell et al. 2010; Mayer et al. 2017b). An additional year was added to the minimum age every year following the initial capture. The sex of the beaver was established by the colour and viscosity of their anal gland secretion, where females have a greyish thick paste and males a more oily secretion with pale white or yellow colour (Rosell and Sun 1999). Based on long-term monitoring, we established that all tagged females were dominant, which means they are the oldest female in the territory and the only one reproducing. Whether the dominant female reproduced each year was determined by increased nipple size, kits being observed in the territory the following autumn, yearlings observed the following year or observations of adults provisioning food to the lodge in spring and summer (Wilsson 1971).

We tagged the captured beavers with two different types of VHF transmitters to track their movements. Seventeen beavers were tagged with Alterra TX30.3A1 intraperitoneal 30$\mathrm{MHz}$ radio transmitter (63 $\mathrm{g}$ ) equipped with a temperature sensor and movement sensor (Alterra (IBN/DLO), 6700 AA Wageningen, the Netherlands). These transmitters were implanted into the peritoneal cavity, and for this study, only the radio signal was utilized, while the temperature and movement data were not used. Beavers tagged with these implants were anesthetized immediately after capture using a mixture of medetomidine $(0.05 \mathrm{mg} / \mathrm{kg})$, ketamine $(5 \mathrm{mg} / \mathrm{kg})$ and butorphanol (0.1 mg/kg) (Ranheim et al. 2004) and released within $5 \mathrm{~h}$ after capture (Sharpe and Rosell 2003). One beaver tagged with an internal implant died post-operatively, while all other beavers were successfully released back into their territory following captures (Ranheim et al. 2004). No negative impact on behaviour or movements was observed in the days following surgery other than an increase in time spent in the lodge the following 2 days (Sharpe and Rosell 2003; Ranheim et al. 2004). Long-term monitoring showed that 
the beavers continued to reside within their territories 17-24 months after tagging (Ranheim et al. 2004). Another 24 beavers were tagged with external tail-mounted transmitters (Advanced Telemetry System, Isanti, Minnesota, USA, Model 16M ear tag for beaver tail, weight $38 \mathrm{~g}$ ), or proximity loggers with VHF transmitters also mounted on the beaver tail (Sirtrack Ltd., Private Bag 1403, Goddard Lane, Havelock North 4157, New Zealand) (Sharpe and Rosell 2003; Campbell 2010). These beavers were not anesthetized as the tail consists mostly of adipose tissue. A small 5-mm hole was made onto one side of the tail, $10 \mathrm{~cm}$ from the base, and the radio transmitter was fitted using a screw, washer and nut through the hole. Each beaver was released within $10 \mathrm{~min}$ after capture and most were observed engaging in normal behaviour shortly after release (Sharpe and Rosell 2003).

\section{Data collection}

Observations of radio-tracked beavers were conducted between March and August 2000, April and August 2001, May and August 2006 and April and September in 2007. It was not possible to record data blind because our study involved focal animals in the field. Tracking of beavers tagged with internal transmitters started 1 week following surgery, while tracking of beavers with external tail transmitters started no sooner than 3 days following capture. Individual beavers were tracked during randomly selected nights from the time they emerged from their lodge after 19:00 until they returned to the lodge after 08:00, which we define as their active period (Campbell 2010). The behaviour of each focal beaver was continuously monitored by two observers in a motorized boat using binoculars and spotlights (Sharpe and Rosell 2003). Such observations from boats have minimal impact on the beavers' behaviour (Rosell and Hovde 2001). To determine seasonal activity budgets, circadian activity rhythms and diet, we registered the beaver's behaviour every minute if it was clearly visible and noted its location every $15 \mathrm{~min}$. The beaver behaviours were categorized as the following: foraging, travelling, in lodge, diving, defensive, alerted, social/grooming or other (see Table S1 for details). The most common activity types, which were used in the analysis, included foraging, traveling and being in the lodge. Foraging observations included all handling of potential food items in the water or on land, which included observations such as felling trees, eating food items close to the water, diving and foraging on aquatic vegetation. Travelling described all movement, either on land or in the water, independent of distance from the lodge. Being in the lodge included all observations of beavers either sitting on top of or directly next to a lodge or being inside the lodge (Table S1). Food items were classified as trees/shrubs, aquatic vegetation or herb/grasses. When possible to observe, the foraged trees/shrubs were categorized as either deciduous or coniferous.

\section{Data preparation}

We used the coordinates of all beaver observations to create a 95\% kernel home range for each family in each year with the adehabitatHR package in $\mathrm{R}$ version 3.6.1 (Calenge 2006; $\mathrm{R}$ Core Team 2019). Beaver observations outside their territory, which are typically explorative trips into other territories, were excluded from the analysis. Beavers often have several lodges and burrows throughout their territory (Żurowski 1992), and several lodge locations were sometimes registered within the same territory during 1 year. To establish which lodge functioned as the beavers' main lodge that year, all observations of a beaver in a lodge or burrow were pooled according to territory and year. We then created a $10 \%$ kernel range of these positions to find the lodge that was used most intensely. For each of these kernel polygons, we estimated the geographical centre point and determined this as the location of the main lodge. Regardless, observations of beavers spending time in lodges other than their main lodge were recorded as being in a lodge. We calculated the Euclidean distance from the main lodge to each beaver observation while outside a lodge, within each territory and year. As the rivers in the study area mostly run straight, and beavers rarely move long distances on land, most observations were made down river or upriver from the main lodge and rarely involved long distances moved on land. The date of each beaver observation was transformed to Julian day where each day was assigned a number, starting from one on January 1 and ending with 365 on December 31 . The time of each observation was transformed to active hour, which means that the first hour of observations from 19:00 to 20:00 became active hour 1 , and the last observations from 07:00 to 08:00 became active hour 13. A few observations of beavers were made outside this principle activity period, but these were subsequently removed from the analysis, as we did not have sufficient observations to model beaver activity during those times. For the first part of the analysis, we modelled the probability of the beavers' main activities (foraging, being in a lodge and travelling), where Julian day and activity hour were used as proxies for seasonal and daily changes. We used a subset of 15-min time point observations for which we had spatial coordinates to factor in the distance to the main lodge. For the second part of the analysis, we explored probability of use of different food items (trees/shrubs, aquatic vegetation and herbs/grasses), using all 1-min time point samples involving foraging.

\section{Statistical analysis}

We used generalized additive mixed models (GAMMs) to evaluate the probability of beavers engaging in each activity, and foraging on different food items, using the R package 'gamm4' and maximum likelihood estimation (ML) (Wood et al. 2017). Penalized regression splines and cross-validation 
were used to find the appropriate level of smoothing (Zuur 2012; Zuur et al. 2014; Wood et al. 2017). We constructed separate sets of candidate models for each activity (foraging, travelling and being in a lodge) and food item (trees/shrubs, aquatic vegetation and herbs/grasses), using the occurrence of that activity or food item as a binomial response variable (exhibiting a focal behaviour or foraging on food item $=1$, exhibiting other behaviours or foraging on other items $=0$ ). For modelling the probability that a given activity would occur at any given point in time, we included the following explanatory variables as splines: Julian day and active hour. We considered a potential interaction between sex and Julian day and active hour to explore whether the sexes had different seasonal activity budgets and circadian activity rhythms. We also included distance to lodge interacting with sex to explore whether males moved further from the lodge than females and age as linear fixed effects. To model the probability that the beavers would use different food items, we included a spline on Julian day interacting with sex and age as a linear fixed effect. We included beaver identity (ID) and year as crossed random factors on the intercept in all candidate models. A model with no fixed effects, but only the random factors, was also included in every candidate model set (Table S2). We used Spearman correlation test with a cut-off value of 0.6 and variance inflation factors (VIF) with a cut-off value of $>3$ as indicators of collinearity between the numerical explanatory variables (Zuur et al. 2009). None of the variables were found to be collinear and they were therefore all retained in the analysis.

For model selection, we used the 'model.sel' function in the MuMIn package (Barton 2011), which compares a priori defined candidate models based on Akaike information criterion (AIC) corrected for a small sample size $\left(\mathrm{AIC}_{\mathrm{c}}\right)$ (Anderson 2007; Zuur et al. 2009; Arnold 2010). An extension of the MuMIn package using a wrapper function was enabled to allow for model comparison using $\mathrm{AIC}_{\mathrm{c}}$ with GAMM models (Barton 2011). If several of the models had a $\triangle \mathrm{AIC}_{\mathrm{c}}$ value (i.e. the difference between the $\mathrm{AIC}_{\mathrm{c}}$ score of any candidate model and the top ranked model) that ranged between 0 and 2, we selected the most parsimonious model to avoid the inclusion of 'pretending variables' (i.e. confounding variables or variables with limited biological importance) (Arnold 2010). We chose to select the most parsimonious model to plot the model effect instead of model averaging due to nested nature of the candidate models with many containing the same variables (Harrison et al. 2018). To validate the models, we plotted the model residuals against each explanatory variable and visually inspected patterns or trends in the residuals (Zuur 2012). All geographical and statistical analyses were conducted using R version 3.6.1 (R Core Team 2019).

\section{Data availability}

The datasets analysed during the current study are available from the USN Research Data Achieve at https://doi.org/10. 23642/usn. 14191427

\section{Results}

\section{Activity budgets}

We analysed 5430 observations of beaver behaviour at 15min intervals during 225 observation nights, which included 20 beaver territories and 41 beavers, of which 16 were females (all dominant) and 25 were males (18 dominants and 7 where offspring from previous years). Ages of the beavers varied from 2 to 12 years. Observations were conducted from March to September, and in each month, 211-1459, 15-min observations were recorded. Being in a lodge was the most common activity accounting for $34 \%$ of all observations, followed by foraging (30\%) and travelling (28\%). Beavers usually foraged alone and were only accompanied by another beaver in $6 \%$ of all foraging observations, which was either an offspring/parent (51\%) or partner (34\%). Males and females did not differ in terms of time spent with a kit while outside the lodge.

We found seasonal activity budgets and circadian activity rhythms in time spent foraging, being in a lodge and travelling (Table 1). The models all explored the probability of the beavers engaging in a certain behaviour in relation to the explanatory variables, and not time spent on each activity, but for simplicity, we refer to the model outcomes as increasing foraging, travelling or time spent in lodge. Two candidate models exploring foraging received similar support, and the most parsimonious contained age, distance to main lodge and active hour, as well as Julian day, yet no sex-specific effects (Table S2). Beavers foraged consistently throughout the study period, and we found no seasonal peaks in foraging activity (Fig. 1a, Table 1). We found a weak daily trend in probability of foraging with less foraging in the evening and a slight increase towards 04:00 followed by a slight decrease during morning (Fig. 2a, Table 1). Beavers foraged more with increasing distance from the main lodge (Fig. 3a, Table 1) and with increasing age (Fig. 4a, Table 1).

The most parsimonious model exploring the probability of being in the lodge contained age, active hour and Julian day interacting with sex (Table S2). Males and females displayed different seasonal trends in time spent in the lodge, with females spending more time in the lodge during spring (MarchMay), while gradually decreasing time spent in the lodge towards late summer. Males also spent more time in the lodge from April to May, and again from August to September, which contrasted with females that were less likely to spend time in the lodge during this time (Fig. 1b, Table 1). Beavers spent most time in the lodge during early evening and late morning (Fig. 2b, Table 1). Distance to lodge was not included as an explanatory variable in the lodge models, but time spent in the lodge increased slightly in older beavers.

The most parsimonious candidate model predicting the probability of travelling contained age, active hour and 
Table 1 Summary of most parsimonious model to predict the probability of beaver foraging, travelling and being in a lodge in spring-late summer during the years 2000, 2001, 2006 and 2007 in South-Eastern Norway. Each model was fitted with a GAMM with year and beaver ID as random factors on the intercept. Observations of beaver activity are collected from 41 beavers $(N=5430)$. Estimates $(\beta)$ and standard errors (SE) are given for the intercept and linear terms. Each spline variable included in the model is specified with effective degrees of freedom (edf) and test statistics (Ch.sq)

\begin{tabular}{|c|c|c|c|c|c|}
\hline Foraging & $\beta$ & SE & Smooth terms & edf & Ch.sq \\
\hline Intercept & -1.7667 & 0.36746 & s(Julian_day) & 1.941 & 1.426 \\
\hline Age & 0.0742 & 0.04197 & s(Active_hou) & 3.523 & 73.256 \\
\hline Distance_lodge & 0.00108 & 0.00012 & & & \\
\hline Travelling & $\beta$ & SE & Smooth terms & edf & Ch.sq \\
\hline Intercept & -1.3447 & 0.42741 & s(Julian_day):SexFemale & 1 & 12.27 \\
\hline Age & -0.111 & 0.03545 & s(Julian_day):SexMale & 6.71 & 84.44 \\
\hline Distance_lodge & 0.00175 & 0.00024 & s(Active_hou) & 6.93 & 50.88 \\
\hline SexMale & 0.77299 & 0.24097 & & & \\
\hline Distance_lodge:SexMale & -0.0013 & 0.00027 & & & \\
\hline Lodge & $\beta$ & SE & Smooth terms & edf & Ch.sq \\
\hline Intercept & -1.1787 & 0.62497 & s(Julian_day):SexFemale & 1.923 & 49.89 \\
\hline Age & 0.11615 & 0.05739 & s(Julian_day):SexMale & 6.932 & 69.82 \\
\hline SexMale & -0.4152 & 0.39969 & s(Active_hou) & 7.32 & 261.08 \\
\hline
\end{tabular}

Julian day and distance to the main lodge interacting with sex (Table S2). The sexes differed slightly in travelling with females being less likely to travel during early spring, yet increasing travelling slightly towards late summer. Males travelled the most from May to July (Fig. 1c). The beavers were less likely to travel in early evening, while they travelled stably throughout the rest of the night, and with a slight increase in the morning (Table S2). Both males and females travelled more with increasing distance from the lodge, yet at the farthest distances, females were more likely to travel than males. Travelling also decreased slightly with increasing age of the beavers.

\section{Food items}

We used 3312 1-min time point samples from 37 beavers in 18 territories, including 13 females (all dominant) and 24 males (16 dominant and 5 offspring from previous years) for analysing the use of different food items. We could identify food items in $81 \%$ of beaver foraging observations. The most common food item were trees/shrubs, which were recorded in $72.8 \%$ of observations. Aquatic vegetation was registered in $16.4 \%$ of foraging observations and herbs/grasses in $10.8 \%$. When the foraged tree type could be identified, deciduous trees/shrubs were the most common tree type in $90.7 \%$ of observations, while $9.2 \%$ were coniferous trees, which were mostly foraged during spring. Two models received equal support in predicting probability of beaver use of trees/ shrubs and aquatic vegetation. The most parsimonious of these included a spline on Julian day as a sex-specific effect (Table S3). This revealed sex-specific differences in the seasonal use of trees/shrubs and aquatic vegetation (Table 2, Fig. $5 \mathrm{a}, \mathrm{b}, \mathrm{c})$. Males used trees/shrubs throughout the whole study period, but with a small decrease during late spring and summer (May-July). Females, however, used trees/shrubs less during two periods of the year, first in mid-April, and then in mid-July, while simultaneously increasing their use of aquatic vegetation (Fig. 5a, b). Males also used more aquatic vegetation in spring. Among the candidate models in predicting the use of herbs/grasses, four models received equal support, and the most parsimonious contained only a spline Julian day, but no sex-specific differences (Table S3). Use of herbs/grasses was highest from May to July, but with overall lower probability of use compared to the two other food items (Table 2, Fig. 5c).

\section{Discussion}

Beavers displayed variation in both seasonal activity budgets and circadian activity rhythms and seasonal trends in the use of different food items, but we only observed some sexspecific differences. We did not find strong seasonal or daily trends in foraging, and there were no differences between the sexes in terms of foraging. This was contrary to expectations of increased female foraging in spring and during the night (a). As predicted, females spent more time in the lodge and less time travelling during spring (a) and subsequently decreased 
a

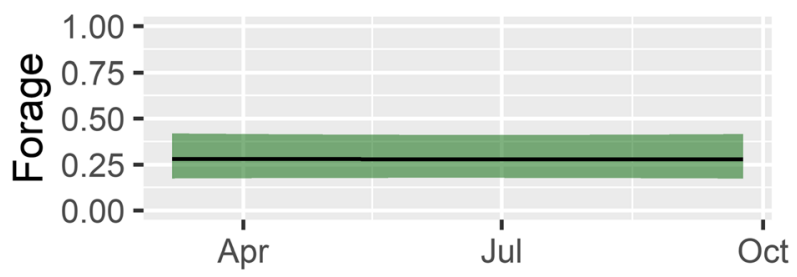

b

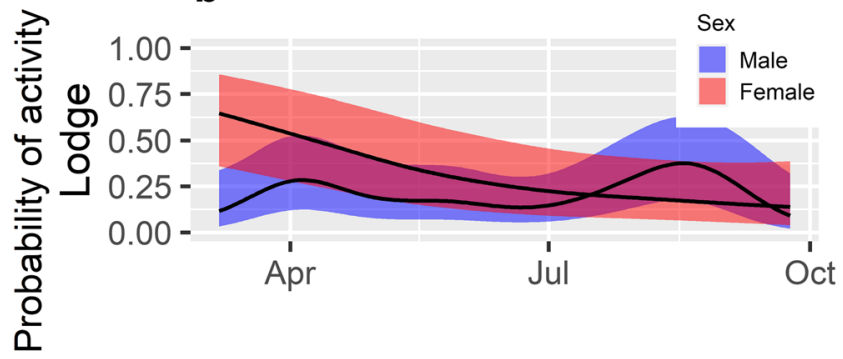

C

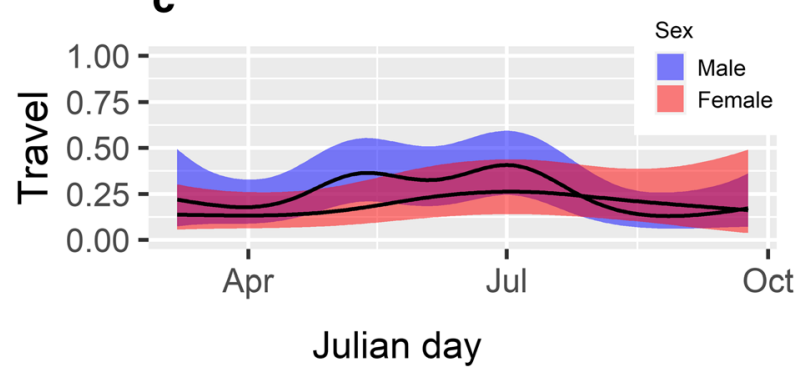

Fig. 1 Predicted effect of Julian day on the probability of Eurasian beaver foraging (a), being in a lodge (b) and travelling (c). Julian day has been converted back to month for plotting purposes. The line represents the estimated smoother produced by a GAMM model, while the polygons represent the $95 \%$ confidence interval around the estimate. The red lines represent females and the blue males. There was no difference between males and females for foraging, and both are represented with a green line. The predictions are based on beaver activity observations from spring to late summer during the years 2000, 2001, 2006 and 2007 in South-Eastern Norway

time spent in lodge and slightly increased travelling in late summer (b). However, the differences in seasonal activity budgets between the sexes were very subtle. Males and females did not differ in terms of circadian activity rhythm. Our prediction that females used nutrient-rich food such as aquatic vegetation and less wood during spring and late summer was supported, but we found no difference in the use of herbs/grasses to the sexes contrary to our prediction (c).

\section{Activity budgets in comparative perspective}

When beavers were outside the lodge, foraging was their main activity followed by travelling, which reaffirms the general trend found in Eurasian beavers by Sharpe and Rosell (2003), but foraging was an even more important daily activity in North American beavers (Gallant et al. 2016). There are several potential explanations why beavers increase foraging a

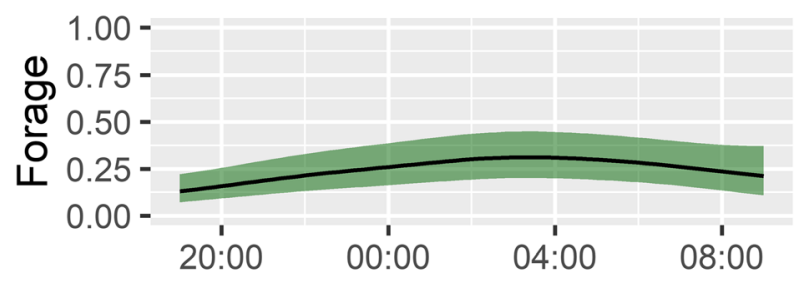

b
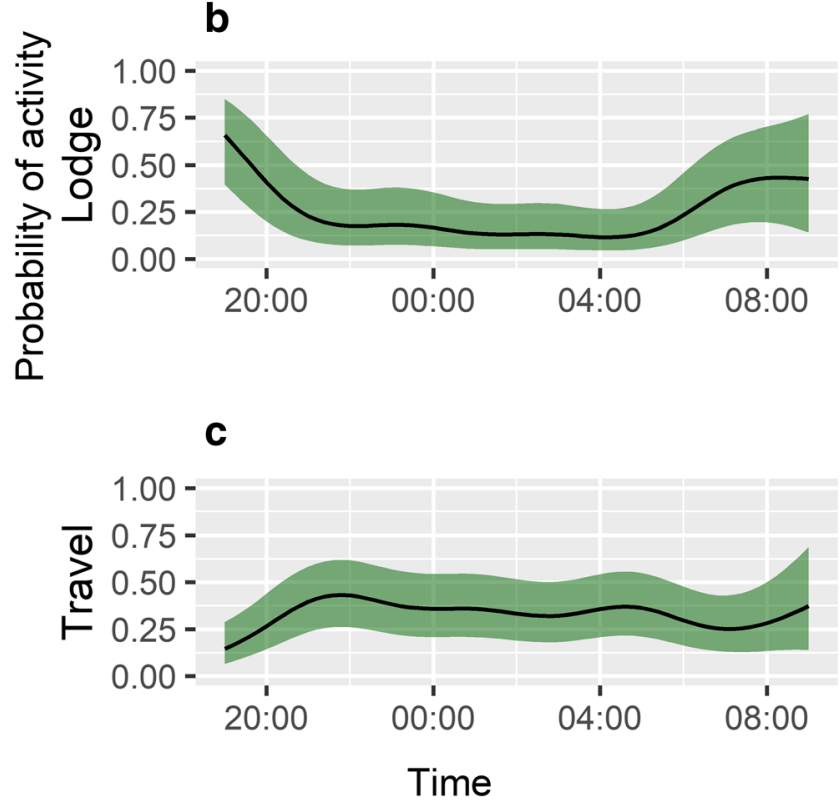

Fig. 2 Predicted effect of active hour on the probability of Eurasian beaver foraging (a), being in a lodge (b) and travelling (c). Active hour represents the beavers' active hours from 19:00 until 08:00 and has been converted back to hour of the day for plotting purposes. The line represents the estimated smoother produced by a GAMM model, while the polygons represent the $95 \%$ confidence interval around the estimates. There was no difference between males and females, and both are represented with a green line. The predictions are based on beaver activity observations from spring to late summer during the years 2000, 2001, 2006 and 2007 in South-Eastern Norway

activity with increasing distance from the lodge. Dominant beavers often spend more time close to the border to the neighbouring territory where they patrol for intruders (Graf et al. 2016), and they might simultaneously forage. Depletion of resources in a beaver territory may lead to both foraging further inland or abandonment of the territory (Goryainova et al. 2014; Hood 2020) and together with buildup of plant defences in browsed vegetation (Bryant et al. 1991) might induce foraging further away. As food sources such as aquatic vegetation and herbs/grasses are only seasonally available, we were surprised not to find an overall increase in foraging during summer. Animals may display very different strategies to deal with fluctuations in food availability and quality even within the same species. In monomorphic red ruffed lemurs, males fed most often during seasonal food abundance, whereas female time spent feeding was stable throughout the year (Vasey 2005). Intense foraging during 
a

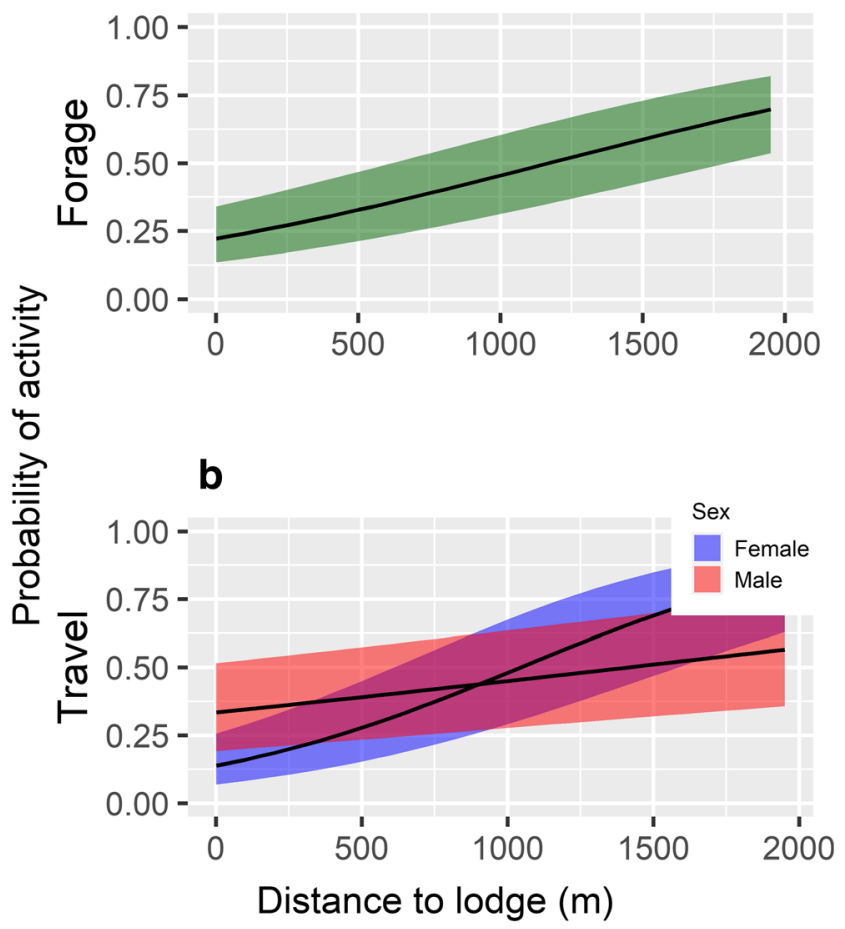

Fig. 3 Predicted effects of distance to the main lodge on the probability of Eurasian beaver foraging (a) and travelling (b). Distance to main lodge represents the Euclidian distance $(\mathrm{m})$. The lines represent the estimated smoother produced by a GAMM model, while the polygons represent the 95\% confidence interval around the estimates. There was no difference between males and females for foraging, and both are represented with a green line. The predictions are based on beaver activity observations from spring to late summer during the years 2000, 2001, 2006 and 2007 in South-Eastern Norway

autumn is common in species that either hibernate or build food caches to get them through the winter (Welch et al. 1997; Lee 2002). Observations of beavers later in the autumn might have revealed larger increases in foraging activity (Potvin and Bovet 1975).

The beavers also displayed distinct circadian activity rhythms. Being in a lodge was, not surprisingly, most likely to occur in late evening and early morning, while they travelled more in the morning. The morning and early evening represents the start and end of the beaver's active period, which may explain these patterns (Sharpe and Rosell 2003). Circadian activity rhythms of animals may also be impacted by season (Pita et al. 2011; Pagon et al. 2013), which we did not account for. However, the subtle temporal variations that we found contrast with Sharpe and Rosell (2003) who found no significant differences in activity patterns when comparing different parts of the season and night. This illustrates how temporal modelling of activity budgets with Julian day as a continuous variable may reveal more subtle variations in animal behaviour.

\section{a}
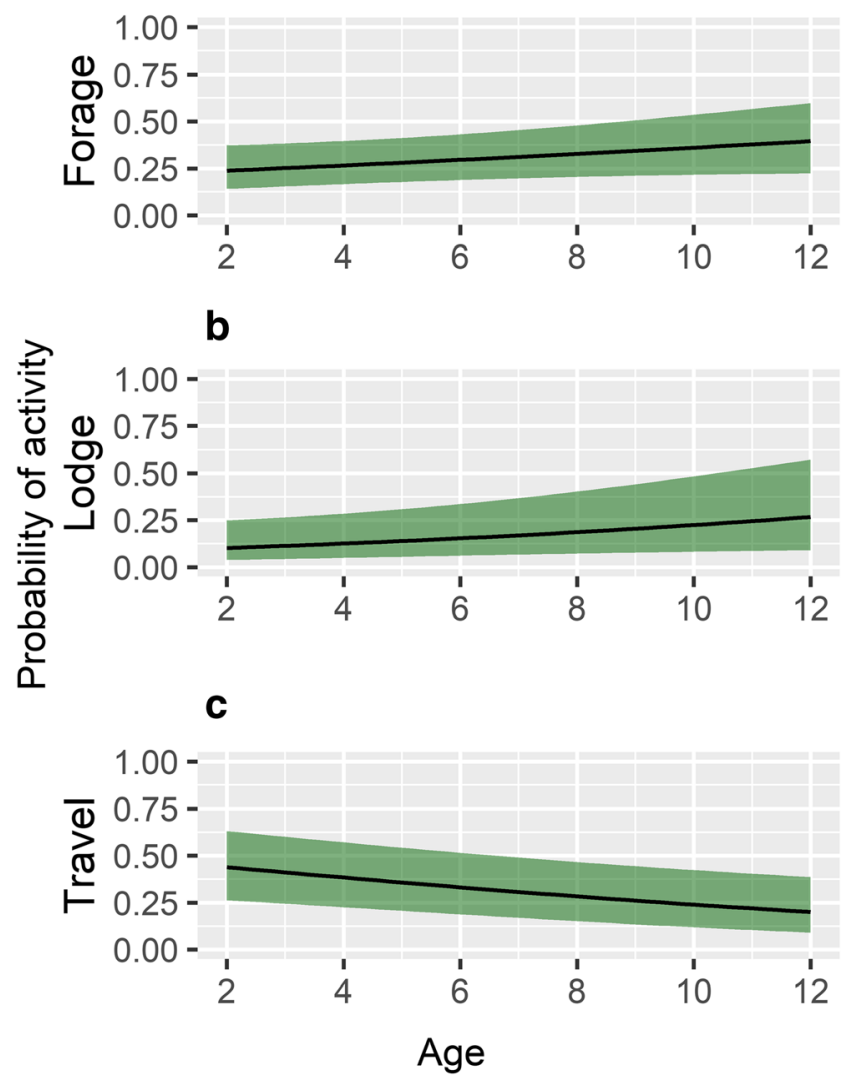

Fig. 4 Predicted effects of age (years) on the probability of Eurasian beaver foraging (a), being in lodge (b) and travelling (c). The line represents the estimated regression line, while the polygons represent the $95 \%$ confidence interval around the estimates. There was no difference between males and females, and both are represented with a green line. The predictions are based on beaver activity observations from spring to late summer during the years 2000, 2001, 2006 and 2007 in SouthEastern Norway

\section{Sex-specific temporal activity budgets}

Due to the energetic cost of gestation and lactation, a stronger increase in foraging activity among females would be expected during the reproductive period (Clutton-Brock et al. 1982; Logan and Sanson 2003; Vasey 2005). Increased time spent foraging has been observed in reproducing females during the reproductive period in other monomorphic animals such as meerkats (Suricata suricatta) (Doolan and Macdonald 1996), tree rats (Thallomys nigricauda) (Eccard et al. 2004), and female birds during incubation (Hedd et al. 2014). Female beavers not foraging more than males in spring may indicate that beavers display traits of an income breeder relying on previously stored fat resources (Rödel et al. 2015). Rainfall during the previous autumn has been shown to be inversely related to beaver reproduction the following year, probably due to rain reducing growth rates of the vegetation (Campbell et al. 2013). Females may display increased foraging activity during autumn in the year prior to reproduction, which we did not explore in this study. In 
Table 2 Summary of the most parsimonious models to predict the probability of beaver use of trees/shrubs, aquatic vegetation and herbs/ grasses in spring-late summer during the years 2000, 2001, 2006 and 2007 in South-Eastern Norway. Observations of beaver activity are collected from 37 beavers $(N=3312)$. Each model was fitted with a GAMM with year and beaver ID as random variables on the intercept. Estimates $(\beta)$ and standard errors (SE) are given for the intercept and linear terms. Each spline variable included in the model is specified with effective degrees of freedom (edf) and test statistics (Ch.sq)

\begin{tabular}{|c|c|c|c|c|c|}
\hline Trees/shrubs & $\beta$ & SE & Splines & edf & Ch.sq \\
\hline Intercept & 1.29913 & 0.40084 & s(Julian_day):SexFemale & 8.052 & 113.14 \\
\hline SexMale & -0.0661 & 0.4615 & s(Julian_day):SexMale & 4.818 & 29.11 \\
\hline Aquatic & $\beta$ & SE & Splines & edf & Ch.sq \\
\hline Intercept & -3.4382 & 0.8064 & s(Julian_day):SexFemale & 7.981 & 180.82 \\
\hline SexMale & 0.2895 & 0.8796 & s(Julian_day):SexMale & 6.997 & 58.05 \\
\hline Herbs/grasses & $\beta$ & SE & Splines & edf & Ch.sq \\
\hline Intercept & -2.5146 & 0.1795 & s(Julian day) & 5.086 & 77.22 \\
\hline
\end{tabular}

monomorphic plain zebra (Equus burchelli) and African oryx (O. gazella), the sexes also did not differ in time spent foraging, but rather in bites taken per minute (Neuhaus and Ruckstuhl 2002; Ruckstuhl and Neuhaus 2009), which we could also not account for due to limited visibility of nocturnal observations.

Female beavers did, however, increase time spent in the lodge during spring, which most likely relates to giving birth and weaning kits (Mayer et al. 2017a). Based on the increased lodge occupancy, a consequential reduction in foraging could be expected, but we did not observe this. The simultaneous reduction in travelling during spring could allow for more time spent in the lodge together with other activities not modelled in the current study (Sharpe and Rosell 2003), while foraging remained unaffected. Both males and females travelled more with increasing distance to the main lodge, and females even more than males at the furthest distances. This does not necessarily mean that females travel further from the lodge, but when observed far away, they are most likely travelling. The furthest distances away from the lodge likely represent the border with another territory, which is regularly patrolled and scent marked by the dominant pair (Rosell et al. 1998; Hohwieler et al. 2018). The purpose of travelling is often difficult to unravel and may relate to both foraging and patrolling (Graf et al. 2016). In roe deer (Capreolus capreolus), which have very low levels of body size dimorphism, males increase activity levels during periods when increased territorial defence is needed, suggesting that differing circadian activity rhythms between the sexes may be more pronounced in periods with different investment in reproduction or territorial protection (Pagon et al. 2013). Young beavers commonly disperse from their natal territory in spring in search of a new territory (Sun et al. 2000), and dominant male beavers may therefore increase patrolling and scent marking efforts during this time (Rosell et al. 1998).

\section{Foraging behaviour and food use}

The beavers were mostly observed foraging solitary, but when accompanied by another beaver, this was either their offspring or partner, which confirms previous studies (Brady and Svendsen 1981; McClanahan et al. 2020). Solitary foraging
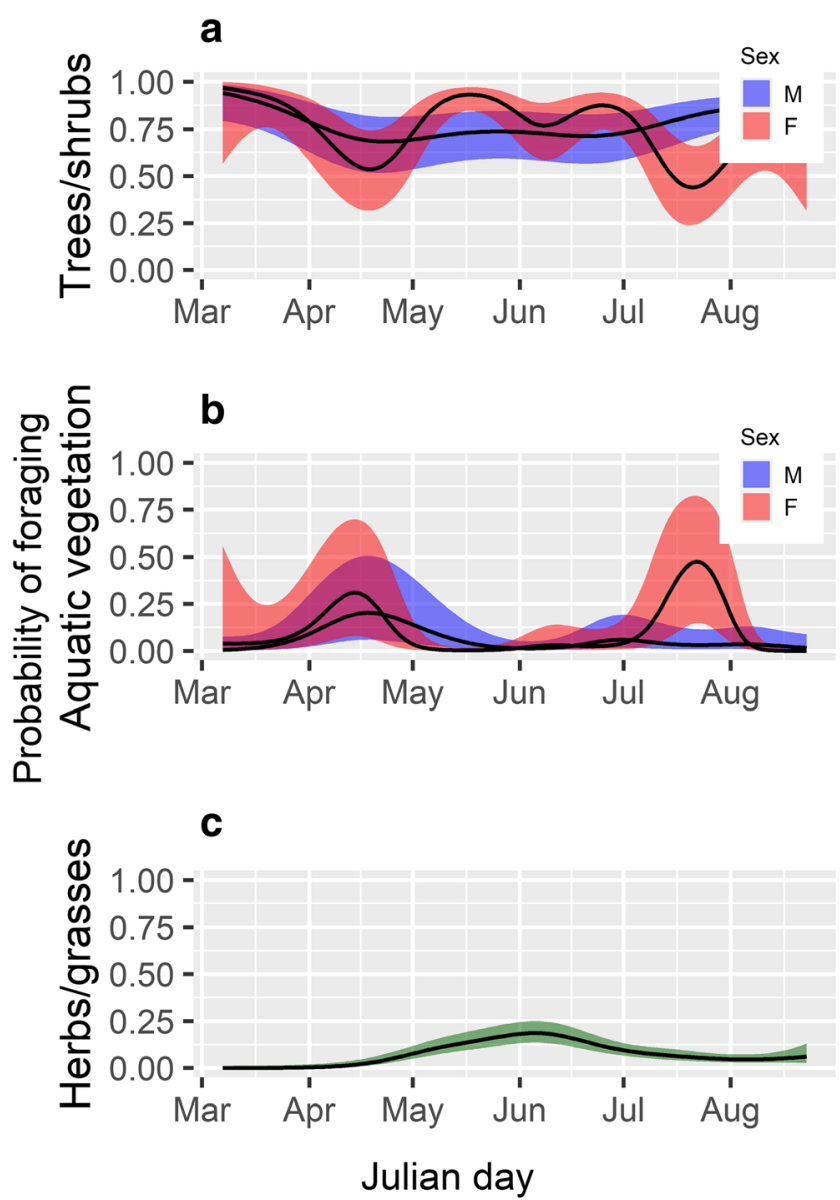

Fig. 5 Predicted effects of the probability of beaver use of trees/shrubs (a), aquatic vegetation (b) and herbs/grasses (c) across the study season (5 March-23 September). The lines represent the estimated smoother based on a GAMM model, while the polygons represent the $95 \%$ confidence interval around the estimates. The red lines represent females and the blue males. There was no difference between males and females for use of herbs/grasses, and both are represented with a green line. The predictions are based on beaver activity observations from spring to late summer during the years 2000, 2001, 2006 and 2007 in South-Eastern Norway 
behaviour of a group-living species may occur due to increased predation risk involved with group foraging (Creel and Creel 2002). Elk (Cervus canadensis), for example, foraged in groups half the size when wolves $(C$. lupus) were present within the same drainage, compared to days when wolves were absent (Creel et al. 2005).

We confirmed that trees/shrubs were the most commonly used food item, followed by aquatic vegetation and herbs/ grasses. Woody material from trees/shrubs is an important part of the beaver diet throughout the year, but has a high crude fibre content that represents a lower quality diet (Bełżecki et al. 2018). Deciduous trees/shrubs were the most common tree type used, but we also observed occasional foraging on conifers during spring (Jenkins 1979; Haarberg and Rosell 2006). Much of the energy in woody material is contained within the cell walls and hard to access, which may explain why beavers supplement with more nutritional foods during summer (Nolet et al. 1995). Another monomorphic species relying mostly on trees as food sources, the Finlayson's squirrel (Callosciurus finlaysonii), also displayed a seasonal shift from buds and tree bark towards more nutritional flowers, seeds and fruits during summer (Bertolino et al. 2004). We found a similar shift towards aquatic vegetation in spring. Several North American studies concluded that aquatic vegetation is a vital part of the beaver diet during summer (Svendsen 1980; Belovsky 1984; Milligan and Humphries 2010; Bergman et al. 2018). Fewer studies have reported Eurasian beavers foraging on aquatic vegetation, but it has been documented from early spring to autumn (Histøl 1989; Law et al. 2014a, 2014b). Beavers are energy maximizers and select food sources that return the most energy over time, but they also require a diverse diet to fulfil their nutritional needs (Belovsky 1984; Doucet and Fryxell 1993; Nolet et al. 1995). Seasonal variations in both availability and nutritional content of food items may have a large impact on choosy opportunistic foragers such as beavers and result in differing diet between males and females due to differing energy budgets.

\section{Sex-specific seasonal food use}

The beavers' use of food items varied according to the season, and males and females differed in seasonal use of trees/shrubs and aquatic vegetation, but not herbs/grasses. Females were less likely to use trees/shrubs between April and May, which is directly prior to the birthing period (Parker and Rosell 2001; Mayer et al. 2017b), but also after the reproductive period in July-August. In both these periods, the reduction of trees/ shrubs was accompanied with a shift towards increased use of aquatic vegetation. Dietary differences between the sexes also occur in other monomorphic species such as thick-billed murres (Uria lomvia) and northern gannet (Morus bassanus) where females dove deeper than males, presumably to select different prey types (Lewis et al. 2002; Elliott et al. 2010).
Differences in foraging locations may also relate to predation risk where one sex forages in high-risk locations, while the partner prioritizes safety over energy maximization and thereby increases overall reproductive success (Elliott et al. 2010). Beavers are most vulnerable to predation when foraging on land (Gable et al. 2018), and females shifting to increased use of aquatics during spring may represent a more risk-aversive foraging strategy (Fryxell and Doucet 1993). Aquatic vegetation also requires less handling time than other food resources (Fryxell and Doucet 1993; Severud et al. 2013), which may be beneficial for females while caring for kits in the lodge.

Different seasonal food use may also relate to nutrient availability and nutritional requirements of reproducing females. A seasonal shift from woody vegetation towards more aquatic vegetation and herbs/grasses is common when beavers diversify their diet in the summer to obtain additional nutrients (Brenner 1964; Nolet et al. 1995; Bełżecki et al. 2018), and is common also in other species foraging on trees (Bertolino et al. 2004). Beaver foraging on conifers mostly occurs during spring, which may suggest selection for certain temporally available nutrients (Jenkins 1979). Sami communities in Fennoscandia used to utilize Scots pine as a traditional food source, especially during spring and summer - most likely because of raised starch levels in the trees during that time (Rautio et al. 2013). Black bears also cause damage to managed conifer stands to gain access to sapwood during spring (Ziegltrum 2004). Beavers shifting towards aquatic vegetation in spring may be influenced by higher available levels of nitrogen, phosphorus and sodium during that time (Nolet et al. 1995; Cebrian and Lartigue 2004; Shurin et al. 2006). Wild animals are commonly sodium-deficient due to low availability, and an increased need for sodium uptake is common in spring, especially for reproducing females during gestation and lactation (Blair-West et al. 1968; Weeks Jr and Kirkpatrick 1976). Moose (Alces alces) also forage on aquatic plants during spring and early summer to fulfil sodium requirements (Fraser et al. 1982, 1984). Nutritional needs may explain the two peaks of female use of aquatic vegetation prior to and after the lactation period.

\section{Conclusion}

Observing beaver behaviour across seasons and nights over multiple years gave us a unique insight into their temporal activity and foraging behaviour. Females likely adapted their seasonal activity budgets to spend more time in the lodge during reproduction, but without reducing foraging activity, while compensating in summer and early autumn with increased travelling and reduction in time spent in lodge. Differences between males and females were especially apparent in the use of different food items, which may relate to varying strategies to deal with predation risk and nutritional 
and energetic requirements of reproducing females. Temporal modelling of activity budgets and foraging allowed us to identify subtle variations in activity budgets and foraging on different food items between the sexes. These differences suggest that seasonal adaptions may be vital for both survival and reproduction of monogamous and monomorphic species.

Supplementary Information The online version contains supplementary material available at https://doi.org/10.1007/s00265-021-03010-7.

Acknowledgements Thank you to Ruairidh D. Campbell and students who participated in the collection of the field data. Thank you to Harry Hirst for digitalizing parts of the dataset; to Anne G. Hertel, Shane Frank and Rasmus M. Mortensen for statistical advice; and to Tess Espey for proofreading the manuscript. Thank you to the three anonymous reviewers and Associate Editor Theodore Stankowich for the insightful comments and suggestions on the manuscript.

Funding Open access funding provided by University Of South-Eastern Norway. This study was financially supported by the University of SouthEastern Norway.

\section{Declarations}

Ethics approval All animal capture and tagging methods were approved by the Directorate of Nature management (00/45-ARTS/VI/GSy, 2001/7552, 05/9639) and the Norwegian Experimental Animal Board (id 742), as well as special permission to capture beavers within the Nature Reserve of Årnesbukta (2000/1808, 2001/1661, 2006/2642). The use of animals adheres to the guidelines set forth by the Animal Behaviour Society/Association for the Study of Animal Behaviour (ASAB/ABS 2020) and guidelines and regulations of the University of South-Eastern Norway.

Conflict of interest The authors declare no conflict of interest.

Open Access This article is licensed under a Creative Commons Attribution 4.0 International License, which permits use, sharing, adaptation, distribution and reproduction in any medium or format, as long as you give appropriate credit to the original author(s) and the source, provide a link to the Creative Commons licence, and indicate if changes were made. The images or other third party material in this article are included in the article's Creative Commons licence, unless indicated otherwise in a credit line to the material. If material is not included in the article's Creative Commons licence and your intended use is not permitted by statutory regulation or exceeds the permitted use, you will need to obtain permission directly from the copyright holder. To view a copy of this licence, visit http://creativecommons.org/licenses/by/4.0/.

\section{References}

Anderson DR (2007) Model based inference in the life sciences: a primer on evidence. Springer, New York

Arnold TW (2010) Uninformative parameters and model selection using Akaike's information criterion. J Wildlife Manage 74:1175-1178. https://doi.org/10.2193/2009-367

Arnold W, Ruf T, Loe LE, Irvine RJ, Ropstad E, Veiberg V, Albon SD (2018) Circadian rhythmicity persists through the polar night and midnight sun in Svalbard reindeer. Sci Rep 8:1-12. https://doi.org/ 10.1038/s41598-018-32778-4

ASAB/ABS (2020) Guidelines for the treatment of animals in behavioural research and teaching. Anim Behav 159:1-11. https://doi.org/10. 1016/j.anbehav.2019.11.002

Barton K (2011) Model selection with MuMIn and GAMM. https://rforge.r-project.org/scm/viewvc.php/*checkout*/pkg/inst/doc/ gamm.pdf?revision $=99 \&$ root $=$ mumin $\&$ pathrev $=103$. Accessed at: 9 March 2021

Belovsky GE (1984) Summer diet optimization by beaver. Am Midl Nat 111:209-222. https://doi.org/10.2307/2425316

Bełżecki G, Miltko R, Kowalik B, Kędzierska A, Demiaszkiewicz AW, Lachowicz J, Giżejewski Z, Obidziński A, Giżejewski Z, McEwan NR (2018) Seasonal variations of the digestive tract of the Eurasian beaver Castor fiber. Mammal Res 63:21-31. https://doi.org/10. 1007/s13364-017-0337-x

Bergman BG, Bump JK, Romanski MC (2018) Revisiting the role of aquatic plants in beaver habitat selection. Am Midl Nat 179:222246. https://doi.org/10.1674/0003-0031-179.2.222

Bertolino S, Mazzoglio PJ, Vaiana M, Currado I (2004) Activity budget and foraging behavior of introduced Callosciurus finlaysonii (Rodentia, Sciuridae) in Italy. J Mammal 85:254-259. https://doi. org/10.1644/BPR-009

Bischof R, Loe LE, Meisingset EL, Zimmermann B, Moorter BV, Mysterud A (2012) A migratory northern ungulate in the pursuit of spring: jumping or surfing the green wave? Am Nat 180:407424. https://doi.org/10.1086/667590

Blair-West J, Coghlan JP, Denton DA, Nelson JF, Orchard E, Scoggins BA, Wright KM, Junquira CL (1968) Physiological, morphological and behavioural adaptation to a sodium deficient environment by wild native Australian and introduced species of animals. Nature 217:922-928. https://doi.org/10.1038/217922a0

Brady CA, Svendsen GE (1981) Social-behaviour in a family of beaver, Castor canadensis. Biol Behav 6:99-114

Brenner FJ (1964) Reproduction of the beaver in Crawford County, Pennsylvania. J Wildlife Manage 28:743-747. https://doi.org/10. $2307 / 3798790$

Brown JS, Laundré JW, Gurung M (1999) The ecology of fear: optimal foraging, game theory, and trophic interactions. J Mammal 80:385399. https://doi.org/10.2307/1383287

Bryant JP, Provenza FD, Pastor J, Reichardt PB, Clausen TP, du Toit JT (1991) Interactions between woody plants and browsing mammals mediated by secondary metabolites. Annu Rev Ecol Evol S 22:431446. https://doi.org/10.1146/annurev.es.22.110191.002243

Burke CM, Montevecchi WA, Regular PM (2015) Seasonal variation in parental care drives sex-specific foraging by a monomorphic seabird. PLoS ONE. 10:e0141190. https://doi.org/10.1371/journal. pone. 0141190

Calenge C (2006) The package "adehabitat" for the R software: a tool for the analysis of space and habitat use by animals. Ecol Model 197: 516-519. https://doi.org/10.1016/j.ecolmodel.2006.03.017

Campbell RD (2010) Demography and life history of the Eurasian beaver Castor fiber. $\mathrm{PhD}$ thesis, Merton College, Oxford, UK

Campbell RD, Rosell F, Nolet BA, Dijkstra VAA (2005) Territory and group sizes in Eurasian beavers (Castor fiber): echoes of settlement and reproduction? Behav Ecol Sociobiol 58:597-607. https://doi. org/10.1007/s00265-005-0942-6

Campbell RD, Newman C, Macdonald DW, Rosell F (2013) Proximate weather patterns and spring green-up phenology effect Eurasian beaver (Castor fiber) body mass and reproductive success: the implications of climate change and topography. Glob Change Biol 19: 1311-1324. https://doi.org/10.1111/gcb.12114

Cebrian J, Lartigue J (2004) Patterns of herbivory and decomposition in aquatic and terrestrial ecosystems. Ecol Monogr 74:237-259. https://doi.org/10.1890/03-4019 
Clutton-Brock TH, Iason GR, Albon SD, Guinness FE (1982) Effects of lactation on feeding behaviour and habitat use in wild red deer hinds. J Zool 198:227-236. https://doi.org/10.1111/j.1469-7998.1982. tb02072.x

R Core Team (2019) R: A language and environment for statistical computing. Computing, R Foundation for Statistical Computing, Vienna, Austria, http://www.R-project.org

Creel S, Creel NM (2002) The African wild dog: behavior, ecology, and conservation. Princeton University Press, Princeton, New Jersey

Creel S, Winnie J Jr, Maxwell B, Hamlin K, Creel M (2005) Elk alter habitat selection as an antipredator response to wolves. Ecology 86: 3387-3397. https://doi.org/10.1890/05-0032

Doolan SP, Macdonald DW (1996) Diet and foraging behaviour of group-living meerkats, Suricata suricatta, in the southern Kalahari. J Zool 239:697-716. https://doi.org/10.1111/j.14697998.1996.tb05472.x

Doucet CM, Fryxell JM (1993) The effect of nutritional quality on forage preference by beavers. Oikos 67:201-208. https://doi.org/10.2307/ 3545464

Drickamer LC, Vessey SH, Jakob EM (2002) Animal behavior, 5th edn. McGraw-Hill, New York

Eccard JA, Meyer J, Sundell J (2004) Space use, circadian activity pattern, and matting system of the nocturnal tree rat Thallomys nigricauda. J Mammal. 85:440-445. https://doi.org/10.1644/BEM039

eKlima (2020) Gridded values for counties, with trend. Norwegian Meteorological Institute, https://seklima.met.no/observations/

Elliott KH, Gaston AJ, Crump D (2010) Sex-specific behavior by a monomorphic seabird represents risk partitioning. Behav Ecol 21: 1024-1032. https://doi.org/10.1093/beheco/arq076

Fraser D, Thompson B, Arthur D (1982) Aquatic feeding by moose: seasonal variation in relation to plant chemical composition and use of mineral licks. Can J Zool 60:3121-3126. https://doi.org/10. 1139/z82-396

Fraser D, Chavez ER, Palohelmo JE (1984) Aquatic feeding by moose: selection of plant species and feeding areas in relation to plant chemical composition and characteristics of lakes. Can J Zool 62:80-87. https://doi.org/10.1139/z84-014

Fryxell JM, Doucet CM (1993) Diet choice and the functional response of beavers. Ecology 74:1297-1306. https://doi.org/10.2307/1940060

Gable TD, Stanger T, Windels SK, Bump JK (2018) Do wolves ambush beavers? Video evidence for higher-order hunting strategies. Ecosphere 9:e02159. https://doi.org/10.1002/ecs2.2159

Gallant D, Bérubé CH, Tremblay E, Vasseur L (2004) An extensive study of the foraging ecology of beavers (Castor canadensis) in relation to habitat quality. Can J Zool 82:922-933. https://doi.org/10.1139/ z04-067

Gallant D, Léger L, Tremblay É, Berteaux D, Lecomte N, Vasseur L (2016) Linking time budgets to habitat quality suggests that beavers (Castor canadensis) are energy maximizers. Can J Zool 94:671676. https://doi.org/10.1139/cjz-2016-0016

Ganzhorn JU, Pietsch T, Fietz J, Gross S, Schmid J, Steiner N (2004) Selection of food and ranging behaviour in a sexually monomorphic folivorous lemur: Lepilemur ruficaudatus. J Zool 263:393-399. https://doi.org/10.1017/S0952836904005394

Gerwing TG, Johnson CJ, Alström-Rapaport C (2013) Factors influencing forage selection by the North American beaver (Castor canadensis). Mamm Biol 78:79-86. https://doi.org/10.1016/j. mambio.2012.07.157

Goryainova ZI, Katsman EA, Zavyalov NA, Khlyap LA, Petrosyan VG (2014) Evaluation of tree and shrub resources of the Eurasian beaver (Castor fiber L.) and changes in beaver foraging strategy after resources depletion. Russ J Biol Invasions 5:242-254. https://doi.org/ 10.1134/S207511171404002X

Graf PM, Mayer M, Zedrosser A, Hackländer K, Rosell F (2016) Territory size and age explain movement patterns in the Eurasian beaver. Mamm Biol 81:587-594. https://doi.org/10.1016/j.mambio. 2016.07.046

Haarberg O, Rosell F (2006) Selective foraging on woody plant species by the Eurasian beaver (Castor fiber) in Telemark, Norway. J Zool 270:201-208. https://doi.org/10.1111/j.1469-7998.2006.00142.x

Halley D, Rosell F (2002) The beaver's reconquest of Eurasia: status, population development and management of a conservation success. Mamm Rev 32:153-178. https://doi.org/10.1046/j.1365-2907.2002. 00106.x

Harrison XA, Donaldson L, Correa-Cano ME, Evans J, Fisher DN, Goodwin CE, Robinson BS, Hodgson DJ, Inger R (2018) A brief introduction to mixed effects modelling and multi-model inference in ecology. PeerJ 6:e4794. https://doi.org/10.7717/peerj.4794

Hedd A, Montevecchi WA, Phillips RA, Fifield DA (2014) Seasonal sexual segregation by monomorphic sooty shearwaters Puffinus griseus reflects different reproductive roles during the pre-laying period. PLoS ONE 9:e85572. https://doi.org/10.1371/journal.pone. 0085572

Hertel AG, Steyaert SM, Zedrosser A, Mysterud A, Lodberg-Holm HK, Gelink HW, Kindberg J, Swenson JE (2016) Bears and berries: species-specific selective foraging on a patchily distributed food resource in a human-altered landscape. Behav Ecol Sociobiol 70: 831-842. https://doi.org/10.1007/s00265-016-2106-2

Histøl T (1989) Sommerdiett hos bever Castor fiber L. i et utvalg av skogsvann i Vennesla kommune. Vest Agder Fauna 42:96-103

Hjønnevåg ME (2020) Selection of aquatic vegetation in river habitats by Eurasian beaver (Castor fiber) in South-Eastern Norway. University of South-Eastern Norway, Norway, MSc thesis

Hohwieler K, Rosell F, Mayer M (2018) Scent-marking behavior by subordinate Eurasian beavers. Ethology 124:591-599. https://doi. org/10.1111/eth.12762

Hood GA (2020) Not all ponds are created equal: long-term beaver (Castor canadensis) lodge occupancy in a heterogeneous landscape. Can J Zool 98:210-218. https://doi.org/10.1139/cjz-2019-0066

Humphries MM, Thomas DW, Hall CL, Speakman JR, Kramer DL (2002) The energetics of autumn mast hoarding in eastern chipmunks. Oecologia 133:30-37. https://doi.org/10.1007/s00442-0021014-5

Hut RA, Kronfeld-Schor N, van der Vinne V, De la Iglesia H (2012) In search of a temporal niche: environmental factors. Progr Brain Res 199:281-304. https://doi.org/10.1016/B978-0-444-59427-3.000174

Jenkins SH (1979) Seasonal and year-to-year differences in food selection by beavers. Oecologia 44:112-116. https://doi.org/10.1007/ bf00346408

Kile NB, Nakken PJ, Rosell F, Espeland S (1996) Red fox, Vulpes vulpes, kills a European beaver, Castor fiber, kit. Can Field-Nat 110:338 339

Krojerová-Prokešová J, Barančeková M, Hamšíková L, Vorel A (2010) Feeding habits of reintroduced Eurasian beaver: spatial and seasonal variation in the use of food resources. J Zool 281:183-193. https:// doi.org/10.1111/j.1469-7998.2010.00695.x

Law A, Bunnefeld N, Willby NJ (2014a) Beavers and lilies: selective herbivory and adaptive foraging behaviour. Freshw Biol 59:224 232. https://doi.org/10.1111/fwb.12259

Law A, Jones KC, Willby NJ (2014b) Medium vs. short-term effects of herbivory by Eurasian beaver on aquatic vegetation. Aquat Bot 116: 27-34. https://doi.org/10.1016/j.aquabot.2014.01.004

Lee TH (2002) Feeding and hoarding behaviour of the Eurasian red squirrel Sciurus vulgaris during autumn in Hokkaido, Japan. Acta Theriol 47:459-470. https://doi.org/10.1007/bf03192470

Lewis S, Benvenuti S, Dall-Antonia L, Griffiths R, Money L, Sherratt TN, Wanless S, Hamer KC (2002) Sex-specific foraging behaviour in a monomorphic seabird. Proc R Soc Lond B 269:1687-1693. https://doi.org/10.1098/rspb.2002.2083 
Logan M, Sanson GD (2003) The effects of lactation on the feeding behaviour and activity patterns of free-ranging female koalas (Phascolarctos cinereus Goldfuss). Aust J Zool 51:415-428. https://doi.org/10.1071/ZO03017

Mayer M, Robstad C, Serra EP, Hohwieler K, Fuchs B, Evans AL, Arnemo JM, Zedrosser A, Rosell F (2017a) Exposure of the Eurasian beaver (Castor fiber) towards hunters during the spring hunt. Department of Natural Sciences and Environmental Health. University College of Southeast Norway. Bø i Telemark, Norway

Mayer M, Künzel F, Zedrosser A, Rosell F (2017b) The 7-year itch: nonadaptive mate change in the Eurasian beaver. Behav Ecol Sociobiol 71:32. https://doi.org/10.1007/s00265-016-2259-Z

Mayer M, Frank S, Zedrosser A, Rosell F (2019) Causes and consequences of inverse density-dependent territorial behavior and aggression in a monogamous mammal. J Anim Ecol 89:577-588. https://oi.org/10.1111/1365-2656.13100

McClanahan K, Rosell F, Mayer M (2020) Minding your own business: low pair cohesion in a territorial, monogamous mammal. Anim Behav 166:119-128. https://doi.org/10.1016/j.anbehav.2020.05. 008

McLellan BN, Hovey FW (1995) The diet of grizzly bears in the Flathead River drainage of southeastern British Columbia. Can J Zool 73: 704-712. https://doi.org/10.1139/z95-082

Milligan HE, Humphries MM (2010) The importance of aquatic vegetation in beaver diets and the seasonal and habitat specificity of aquatic-terrestrial ecosystem linkages in a subarctic environment. Oikos 119:1877-1886. https://doi.org/10.1111/j.1600-0706.2010. 18160.x

Mott CL, Bloomquist CK, Nielsen CK (2011) Seasonal, diel, and ontogenetic patterns of within-den behavior in beavers (Castor canadensis). Mamm Biol 76:436-444. https://doi.org/10.1016/j. mambio.2010.09.002

Neuhaus P, Ruckstuhl K (2002) The link between sexual dimorphism, activity budgets, and group cohesion: the case of the plains zebra (Equus burchelli). Can J Zool 80:1437-1441. https://doi.org/10. 1139/z02-126

Nielsen JM, Clare EL, Hayden B, Brett MT, Kratina P (2018) Diet tracing in ecology: method comparison and selection. Methods Ecol Evol 9: 278-291. https://doi.org/10.1111/2041-210X.12869

Nolet BA, Rosell F (1994) Territoriality and time budgets in beavers during sequential settlement. Can J Zool 72:1227-1237. https:// doi.org/10.1139/z94-164

Nolet BA, Hoekstra A, Ottenheim MM (1994) Selective foraging on woody species by the beaver Castor fiber, and its impact on a riparian willow forest. Biol Conserv 70:117-128. https://doi.org/10. 1016/0006-3207(94)90279-8

Nolet BA, van der Veer PJ, Evers E, Ottenheim MM (1995) A linear programming model of diet choice of free-living beavers. Neth $\mathrm{J}$ Zool 45:315-337. https://doi.org/10.1163/156854295X00339

Novak M (1999) Beaver. In: Novak M, Baker JA, Obbard ME, Mallock $B$ (eds) Wild furbearer management and conservation in North America. Queens Printer for Ontario, Toronto, Canada

Owen-Smith N, Fryxell J, Merrill E (2010) Foraging theory upscaled: the behavioural ecology of herbivore movement. Phil Trans R Soc B 365:2267-2278. https://doi.org/10.1098/rstb.2010.0095

Pagon N, Grignolio S, Pipia A, Bongi P, Bertolucci C, Apollonio M (2013) Seasonal variation of activity patterns in roe deer in a temperate forested area. Chronobiol Int 30:772-785. https://doi.org/10. 3109/07420528.2013.765887

Parker H, Rosell F (2001) Parturition dates for Eurasian beaver Castor fiber: when should spring hunting cease? Wildlife Biol 7:237-241. https://doi.org/10.2981/wlb.2001.015

Pedersen HC, Follestad A, Gjershaug JO, Nilsen EB (2016) Statusoversikt for jaktbart småvilt. NINA Rapport 1178, Trondheim

Pelletier F, Festa-Bianchet M (2004) Effects of body mass, age, dominance and parasite load on foraging time of bighorn rams, Ovis canadensis. Behav Ecol Sociobiol 56:546-551. https://doi.org/10. 1007/s00265-004-0820-7

Pérez-Barbería FJ, Gordon IJ, Pagel M (2002) The origins of sexual dimorphism in body size in ungulates. Evolution 56:1276-1285. https://doi.org/10.1111/j.0014-3820.2002.tb01438.x

Pita R, Mira A, Beja P (2011) Circadian activity rhythms in relation to season, sex and interspecific interactions in two Mediterranean voles. Anim Behav 81:1023-1030. https://doi.org/10.1016/j. anbehav.2011.02.007

Potvin CL, Bovet J (1975) Annual cycle of patterns of activity rhythms in beaver colonies (Castor canadensis). J Comp Physiol 98:243-256. https://doi.org/10.1007/bf00656972

Ranheim B, Rosell F, Haga HA, Arnemo JM (2004) Field anaesthetic and surgical techniques for implantation of intraperitoneal radio transmitters in Eurasian beavers Castor fiber. Wildlife Biol 10:11-15. https://doi.org/10.2981/wlb.2004.004

Rautio AM, Norstedt G, Östlund L (2013) Nutritional content of scots pine inner bark in northern Fennoscandia. Econ Bot 67:363-377. https://doi.org/10.1007/s12231-013-9254-3

Richter L, Balkenhol N, Raab C, Reinecke H, Meißner M, Herzog S, Isselstein J, Signer J (2020) So close and yet so different: the importance of considering temporal dynamics to understand habitat selection. Basic Appl Ecol 43:99-109. https://doi.org/10.1016/j.baae. 2020.02.002

Roberts TH, Arner DH (1984) Food habits of beaver in east-central Mississippi. J Wildlife Manag 48:1414-1419. https://doi.org/10. $2307 / 3801808$

Rödel HG, Valencak TG, Handrek A, Monclús R (2015) Paying the energetic costs of reproduction: reliance on postpartum foraging and stored reserves. Behav Ecol 27:748-756. https://doi.org/10. 1093/beheco/arv217

Rosell F, Hovde B (2001) Methods of aquatic and terrestrial netting to capture Eurasian beavers. Wildlife Soc B 29:269-274 http://www. jstor.org/stable/3784008

Rosell F, Sun LX (1999) Use of anal gland secretion to distinguish the two beaver species Castor canadensis and Castor fiber. Wildlife Biol 5:119-123. https://doi.org/10.2981/wlb.1999.015

Rosell F, Bergan F, Parker H (1998) Scent-marking in the Eurasian beaver (Castor fiber) as a means of territory defense. J Chem Ecol 24: 207-219. https://doi.org/10.1023/A:1022524223435

Rosell F, Zedrosser A, Parker H (2010) Correlates of body measurements and age in Eurasian beaver from Norway. Eur J Wildlife Res 56:4348. https://doi.org/10.1007/s10344-009-0289-9

Ruckstuhl KE (2007) Sexual segregation in vertebrates: proximate and ultimate causes. Integr Comp Biol 47:245-257. https://oi.org/10. 1093/icb/icm030

Ruckstuhl KE, Neuhaus P (2009) Activity budgets and sociality in a monomorphic ungulate: the African oryx (Oryx gazella). Can J Zool 87:165-174. https://doi.org/10.1139/Z08-148

Ruckstuhl KE, Clutton-Brock T, Neuhaus P (2005) Sexual segregation and the ecology of the two sexes. Cambridge University Press, Cambridge, UK

Severud WJ, Windels SK, Belant JL, Bruggink JG (2013) The role of forage availability on diet choice and body condition in American beavers (Castor canadensis). Mamm Biol 78:87-93. https://doi.org/ 10.1016/j.mambio.2012.12.001

Shaffer SA, Costa DP, Weimerskirch H (2003) Foraging effort in relation to the constraints of reproduction in free-ranging albatrosses. Funct Ecol 17:66-74. https://doi.org/10.1046/j.1365-2435.2003.00705.x

Sharpe F, Rosell F (2003) Time budgets and sex differences in the Eurasian beaver. Anim Behav 66:1059-1067. https://doi.org/10. 1006/anbe.2003.2274

Shurin JB, Gruner DS, Hillebrand H (2006) All wet or dried up? Real differences between aquatic and terrestrial food webs. Proc R Soc Lond B 273:1-9. https://doi.org/10.1098/rspb.2005.3377 
Speakman JR (2008) The physiological costs of reproduction in small mammals. Phil Trans R Soc B 363:375-398. https://doi.org/10. 1098/rstb.2007.2145

Sun L (2003) Monogamy correlates, socioecological factors, and mating systems in beavers. In: Reichard UH, Boesch C (eds) Monogamy: mating strategies and partnerships in birds, humans and other mammals Cambridge University Press, Cambridge, UK

Sun L, Müller-Schwarze D, Schulte BA (2000) Dispersal pattern and effective population size of the beaver. Can J Zool 78:393-398. https://doi.org/10.1139/z99-226

Svendsen GE (1980) Seasonal change in feeding patterns of beaver in Southeastern Ohio. J Wildlife Manage 44:285-290. https://doi.org/ $10.2307 / 3808390$

Swinnen KRR, Hughes NK, Leirs H (2015) Beaver (Castor fiber) activity patterns in a predator-free landscape. what is keeping them in the dark? Mamm Biol 80:477-483. https://doi.org/10.1016/j.mambio. 2015.07.006

Vasey N (2005) Activity budgets and activity rhythms in red ruffed lemurs (Varecia rubra) on the Masoala Peninsula, Madagascar: seasonality and reproductive energetics. Am J Primatol 66:23-44. https://doi.org/10.1002/ajp.20126

Weeks HP Jr, Kirkpatrick CM (1976) Adaptations of white-tailed deer to naturally occurring sodium deficiencies. J Wildlife Manage 40:610 625. https://doi.org/10.2307/3800555

Welch CA, Keay J, Kendall KC, Robbins CT (1997) Constraints on frugivory by bears. Ecology. 78:1105-1119. https://doi.org/10. 1890/0012-9658(1997)078[1105:COFBB]2.0.CO;2

Wilsson L (1971) Observations and experiments on the ethology of the European beaver (Castor fiber L.). PhD thesis, Stockholm University, Stockholm, Sweden

Wood S, Scheipl F, Wood MS (2017) Package 'gamm4'. Am Stat 45:339
Ydenberg RC, Krebs JR (1987) The tradeoff between territorial defense and foraging in the great tit (Parus major). Am Zool 27:337-346. https://doi.org/10.1093/icb/27.2.337

Ziegltrum GJ (2004) Efficacy of black bear supplemental feeding to reduce conifer damage in western Washington. J Wildlife Manage 68: 470-474. https://doi.org/10.2193/0022-541X(2004)068[0470: EOBBSF]2.0.CO;2

Zoller H, Drygala F (2013) Activity patterns of the invasive raccoon dog (Nyctereutes procyonoides) in North East Germany. Folia Zool 62: 290-296. https://doi.org/10.25225/fozo.v62.i4.a6.2013

Zub K, Szafrańska P, Konarzewski M, Redman P, Speakman JR (2009) Trade-offs between activity and thermoregulation in a small carnivore, the least weasel Mustela nivalis. Proc R Soc Lond B 276: 1921-1927. https://doi.org/10.1098/rspb.2008.1936

Żurowski W (1992) Building activity of beavers. Acta Theriol 37:403411

Żurowski W, Kisza J, Kruk A, Roskosz A (1974) Lactation and chemical composition of milk of the European beaver (Castor fiber L.). J Mammal 55:847-850. https://doi.org/10.2307/1379417

Zuur AF (2012) A beginner's guide to generalized additive models with R. Highland Statistics Limited Newburgh, New York

Zuur AF, Ieno EN, Walker N, Saveliev AA, Smith GM (2009) Mixed effects models and extensions in ecology with R. Springer Science and Business Media, New York

Zuur AF, Saveliev AA, Ieno EN (2014) A beginner's guide to generalised additive mixed models with R. Highland Statistics, New York

Publisher's note Springer Nature remains neutral with regard to jurisdictional claims in published maps and institutional affiliations. 